\title{
URBANIZATION PROCESSES IN THE KYRGYZ REPUBLIC. CASE STUDY: THE CITY OF BISHKEK
}

\author{
M. DYLDAEV 1
}

\begin{abstract}
Urbanization Processes in the Kyrgyz Republic. Case Study: the City of Bishkek. In the Kyrgyz Republic the urban population is 34\% and on its territory there are 31 cities at different levels. About $60 \%$ of the urban population lives in two cities - Bishkek (the capital) and Osh. At present, the urban population is about $1,987,000$ inhabitants. The main specificity is that urbanization processes develop in a mountain territorial location. Urban areas are mostly located in valleys and low mountain areas, with the exception of some urban systems, which are located in the middle part. An important task at the moment is to find a solution for the socio-economic problems of small towns. In this regard, there is need for an integrated treatment of the inevitable new residential policy - shaping Bishkek agglomeration with surrounding satellite cities.
\end{abstract}

Keywords: urbanization, sustainable development, agglomeration, unplanned urbanization, cities satellites plan

\section{INTRODUCTION}

The territory of the Kyrgyz Republic stretches from west to east for 900 $\mathrm{km}$, from north to south for $410 \mathrm{~km}$, and is located approximately between $39^{\circ}$ and $43^{\circ}$ North latitude. The area of the territory of Kyrgyzstan is 199,900 square km. It borders to the North with the Republic of Kazakhstan, to the West - with Uzbekistan, in the South-West - with the Republic of Tajikistan, in the South-East with China.

In the Kyrgyz Republic the process of urbanization in the main proceeded after industrialization. In 1941 and 1942, about 30 factories were moved to Kyrgyzstan and partially reallocated to military production. They were mainly located in the Chui region and Bishkek. In those same years, the first large irrigation canals were built, which led to an increase in agricultural production (Urbanization in Central Asia, 2013).

\footnotetext{
${ }^{1}$ Bishkek Humanities University, Kyrgyz Republic, e-mail: mdyldaev@gmail.ru
} 
According to local experts, an urbanization policy was conducted in the post-Soviet period in Kyrgyzstan. Key government's efforts were aimed against the economic crisis in which the country found itself after the break of economic ties with the former Soviet Union economic complex.

The development of the cities as elements of the settlement system allows to more clearly identify their problems and to find solutions. Accordingly, small and medium-sized cities of the country can be divided into the following groups: centers of the mining industry; agribusiness, in the case of the administrative centers of agricultural areas; cities with processing profile enterprises; transportation centers and recreation centers.

From a historical evolution of the forms of settlement to replace the traditional types of populated areas, developing relatively autonomously, comes a new "group" formed of highly concentrated settlement resulting from the close placement of the settlements and the formation of intense relationships between them. These are the urban agglomerations (CA) - intensively developing worldwide clusters of settlements, consisting of dozens, and sometimes hundreds of localities, including rural settlements, even closely related to one another. There is no unified terminology to refer to such a concentration of the population. Along with the term "agglomeration", the terms "a constellation of cities", "areas of the big cities," "local settlement system", "group settlement system" are used.

In the Kyrgyz Republic, the category of cities of regional importance includes settlements that are administrative, economic and cultural centers, with industrial companies, utilities and housing, an extensive network of educational, cultural, educational, medical and shopping facilities, with a population of not less than 20,000 people.

The category of cities of local importance includes administrative, economic and cultural centers, which have a production and social infrastructure, an extensive network of educational, cultural, educational, medical and shopping facilities, with a population of not less than 10,000 people.

The category of urban settlements can be classified as settlements which are located on the territory of economically important facilities (industrial enterprises, construction sites, railway stations, etc.), or in areas that have a therapeutic value if they have reached a certain level of improvement, with a population of more than 2,000 inhabitants.

In exceptional cases, the category of urban settlements may comprise settlements with smaller population, but they need to be administrative, economic and cultural centers, and to have a certain perspective of further economic development and population growth. (Law no. 65/ April 2008). 
However, small and medium-sized cities are part of the territorial structure of the economy. Therefore, they must find a place in the territorial development strategy. In particular, public events are important, providing support for small and medium-sized cities by attracting additional funds, which will allow to remove the urban socio-economic tensions.

The priority of further improving the system of settlements should be the transition from the extensive to the intensive phase of urbanization. In this reference frame, the settlement system will develop towards large metropolitan areas in each of the regions of the country and settlements that form the area will gravitate towards them, reaching higher urban living standards.

Table 1. The distribution of urban population in the Kyrgyz Republic by category (1989-2012)

\begin{tabular}{|l|r|r|r|r|r|r|r|r|}
\hline \multirow{2}{*}{ Category of the city } & \multicolumn{4}{|c|}{ Amount } & \multicolumn{3}{c|}{ Population (thousand people) } \\
\cline { 2 - 9 } & $\mathbf{1 9 8 9}$ & $\mathbf{1 9 9 9}$ & $\mathbf{2 0 0 9}$ & $\mathbf{2 0 1 2}$ & $\mathbf{1 9 8 9}$ & $\mathbf{1 9 9 9}$ & $\mathbf{2 0 0 9}$ & $\mathbf{2 0 1 2}$ \\
\hline Small (up to 50,000) & 15 & 15 & 20 & 19 & 366.4 & 379.7 & 444.7 & 478.9 \\
\hline Medium (50-100,000) & 4 & 3 & 3 & 4 & 259.2 & 194.1 & 205.6 & 274.0 \\
\hline $\begin{array}{l}\text { Large (>100,000) } \\
\text { thousand and higher) }\end{array}$ & 2 & 2 & 2 & 2 & 821.4 & 958.8 & $1,054.7$ & $1,130.2$ \\
\hline Total & $\mathbf{2 1}$ & $\mathbf{2 0}$ & $\mathbf{2 5}$ & $\mathbf{2 5}$ & $\mathbf{1 , 4 4 7 . 0}$ & $\mathbf{1 , 5 3 2 . 7}$ & $\mathbf{1 , 7 0 5 . 1}$ & $\mathbf{1 , 8 8 3 . 2}$ \\
\hline \hline
\end{tabular}

By their nature, urban areas in the Kyrgyz Republic have a number of specificities that are characteristic of the mountainous areas of the world: a) urban settlements and settlements in general formed in a mountainous terrain (amplitude height above sea level is $450-7439 \mathrm{~m}$ ), the uppermost settlement and some villages are situated at an altitude of more $3000 \mathrm{~m}$.; b) Most of the settlements are located in the valley of the foothills, and have the character of uneven distribution (almost 80\% of the settlements concentrate in $15 \%$ of the country); c) there is a special type of urbanization that is inherent in mountainous terrain, and different from the classical types of urbanization, the so-called "mountain character"; d) after the declaration of independence, various socio-economic problems emerged concerning employment, migration of population and the "spontaneous" movement of the population on the territory impacting generally on urbanization and planning.

\section{METHODOLOGY}

The term "agglomeration" in relation to resettlement was introduced by the French geographer M. Rouget, according to which agglomeration occurs when the concentration of urban activities goes beyond administrative borders and spread to the neighboring villages (Lappo, 1997). 
The most common are two ways of formation of agglomerations, "from the city" and "from the area".

The formation of agglomeration "from the city" occurs when a certain "threshold" in the town development makes that it is not possible to locate some urban functions on its territory so they are located in satellite settlements. At the same time there are facilities in its suburban area that are attracted to the city itself.

The development of the agglomeration "from the area" is typical for resource zones, for instance in areas of the mining industry, where there is a group of villages or towns that share one specialization. Over time, one of them having a better position and better conditions for development, becames the center, and the rest of the settlements - its satellites.

In a paper concerning urban issues, Pertsik (1991) identified the main methodological aspects which in our view constitute a complete picture and is characterized by a modern concept. The main directions in the field of urbanization have been identified: the development of a geographical theory of the city; strengthening links between fundamental concepts (interaction of territorial patterns of production and increased resettlement contrast, the use of the effect of the interconnected settlements, including the analysis of the potential of large cities and agglomerations, the analysis of economic and geographical position, the system analysis of the environment and taking into account the long-term consequences of its transformation, etc.); the development of geographical approaches and urban development of prediction methods (especially the methods of quantitative measurements and qualitative assessments to establish the theory of inertia of urban systems, etc.); identification of the objective laws that underlie the processes of city development; creation of the theory and morphology analysis methods for urbanized systems of different taxonomic rank (demographic, socio - geographical, urban planning mark in their different areas and parts has to be different, often opposite directions, which requires a comprehensive study of thorough identification, modeling of these zones and parts). It is necessary to develop new approaches to the analysis of economic and geographical systems of urban entities, their population cycles of life, the modeling of social conditions in the different areas and parts of the management of the development of the agglomeration, the mathematical modeling of urban systems and much more.

Special attention in our opinion should be given to the methodological aspects provided by G.M. Lappo (1997), in a study of the factors regarding the urban development theory. They have a significant relevance in the concept of urbanization and the degree of interaction between the natural environment and the urban systems. 


\section{OBJECT OF STUDY}

The capital of the Kyrgyz Republic, Bishkek, is located in the North of the country, in the central part of the Chui Valley in the piedmont plain of the Kyrgyz Ala-Too at altitudes of 700-900 meters above sea level. It has developed for more than a century of its existence from a small post office into a major industrial and cultural center of the country. In the last 14-15 years, the rate of urbanization was spontaneously high. Around the city the so-called housing estates expanded. They are built up with low-rise buildings without infrastructure, which significantly worsened the sanitary-epidemiological and ecological situation.

According to the classification by J. Gibbs (1963, the theory of "differential urbanization"), the current state of Kyrgyzstan capital corresponds to the $4^{\text {th }}$ stage of urbanization: "Concentration of population in major cities and at the same time reducing the number of small settlements". However, there is a local feature of the urbanization process - it takes place in an exaggerated way as there is population concentrated in excess in one city, about $20 \%$ of the total population. At present, the population of Bishkek according to independent experts is about 1.3 million inhabitants. Given the annual population growth rate of $2-3 \%$, the estimated number of population of the city in 25 years can double and would exceed 2.5 million inhabitants. And this is without considering the possible political upheavals, demographic "booms" and waves of internal migration.

Target demographics, traffic problems and engineering - geological constraints cause the use of flexible linear-ring forms of urban plans and sectoral planning structure. The combination of a sectoral model, when functional areas are linked to the main thoroughfares of the radial and linear model and when the areas are located parallel to each other, allow for a full solution to the complex problems of urban Bishkek (NISI, 2015).

As one of the local experts, K. J. Bokonbaev (2014), noted: "The uncontrolled urbanization causes the problem of food security. All over the world there is not enough arable land, nearly a billion people lack food products. In Bishkek, 30-40 years ago, the land around the capital, where slums are now built, was arable on the site of agricultural land we are building a concrete jungle, depriving people of food safety basics. This is not normal. Of course, it is possible to expand the city, covering the entire territory from Belovodsk to Tokmak, building a huge metropolis on the site instead of fields, but it will end in disaster, because the agricultural land will disappear while the need to feed the population - no" (Dyldaev \& Bokonbaev, 2008).

On the basis of the main features of the satellite towns, the transport accessibility (1.5 hours) and the concentration of production and labor in them, the satellite cities of Bishkek agglomeration could become a part of the city. In 
this way, Bishkek would expand to the East including Tokmok and to the West, to Kara-Balta city and in the future they could be joined by the cities of Kaindy (West) and Kemin (East).

An important task at the moment is to find a solution for the socio-economic problems of small towns. In this regard, there is need for an integrated approach of the inevitable new residential policy - shaping Bishkek agglomeration with surrounding satellite cities.

Of particular note is the negative impact of the Bishkek industrial unit on the land resources in Chu Valley. In recent years, the distinctive feature of cities in developing countries is a sharp rise in their population due to immigrants from the countryside. This situation is typical for Bishkek, the capital of Kyrgyzstan. The growth of urban population usually leads to the expansion of the territories covered by these cities. The issue is that the surroundings consist of very valuable agricultural land. The urbanization of these areas, the replacement of agricultural land by governmental residential areas makes it difficult to supply the same urban population with food. This negative impact of urbanization is characteristic not only for the surrounding areas of Bishkek, but also for Chui and Fergana valleys. The irrigated fields around our cities are among the most valuable resources according to the website www.central-asians.ru.

Regarding the current situation in Bishkek, the exaggerated development of the city came to the point where the existing of socio-economic problems have become ubiquitous and negatively affect the quality of life of Bishkek. It is wellknown that the urban infrastructure has suffered an overpressure in recent years. The city began to choke because of the traffic which sharply escalated the problem of connecting people to the public resources, new homes, as the wave of migration is difficult to control.

However, one can not underestimate the danger of unregulated development of the surrounding communities, as evidenced by the experience of many countries caught in such circumstances where the imbalance between the city center and the small towns surrounding it lead to a crisis. The underdeveloped periphery, especially represented by small towns brings a significant limitation to the development of capital.

In general, analyzing the overall environmental situation, the current environmental crisis in its main features is visible in the following areas: the accumulated volume of industrial, agricultural and household waste, which disrupts the natural biological cycles and significantly reduces the area of productive land; the dumping of huge quantities of industrial and domestic waste water in river systems without treatment; the pollution with fuel combustion products (soot, sulfur oxides, etc.) impacting on the composition of the urban air; the sharp increase in the range of noise, vibration, radiation, adversely affecting the vital functions of plants, animals and people (Dyldaev \& Bokonbaev, 2008). 
All these processes affect the degree of ecological balance in the urban areas and the number of zones with different environmental and economic regimes - development zones, the ecologically balanced areas, the buffer zones and compensation areas.

One of the main criteria for achieving sustainable development and ecological balance in the urban system of Kyrgyzstan is to determine the environmental capacity of the area which accounts for the demographic capacity relative to environmental components.

In addition to the demographic capacity of territory, other engineering and environmental characteristics are also important: the reproductive capacity of the territory, the geochemical activity and the overall environmental capacity.

Equally important for the sustainable development of urban areas is the assessment applied in the evaluation of environmental damage, which requires additional costs associated with the need to eliminate the pollution of the environment, to stop its destruction and the depletion of mineral resources and to restore the natural ecosystems. Environmental damage has reached enormous proportions, adversely affecting the economy of the city. The changing properties of nature provide that the stability of the resource base is lost. It affects the national wealth, it changes the conditions of labor force reproduction and the way people live.

It is clear that there is a large scale of anthropogenic impact in the cities and other populated places on the components of the natural environment which is also related to the deep global climate changes, the degree of urbanization, the forms of organization of the economy, the resettlement and the growth of industrial enterprises. An important factor is the uneven and sometimes chaotic location of the sources of pollution within the urban area. This in turn leads to the fact that the level of negative impact on vegetation, wildlife, and other natural elements is not the same in different functional areas of the city.

A key result of the urbanization policy and territorial development should not be a simple increase in the proportion of the urban population, but a fundamental change in the spatial pattern of the region.

Urbanization thus becomes a new challenge for cities and urban infrastructure, which belongs to the category of the most energy-intensive, laborintensive and capital-intensive industries. With the steady rise in prices for energy resources it becomes more problematic to keep the central heating system, gas and other spheres of public utilities, which traditionally occupy a leading position in terms of consumption of non-renewable energy resources. It is expected in the near future that the Central Asian governments will be forced to resort to rationing the release of natural gas, electric and thermal energy and to introduce new town planning norms and standards. Thus, urban studies represent a new challenge in the field of technological renovation and modernization of the urban economy, and not only of the city. 


\section{CONCLUSIONS}

Urban development processes in the Kyrgyz Republic have been set off gradually and must go through the following stages of urbanization:

- Spot the development of cities. The transformation of the rural economy into an urban one, the agricultural functions in industrial ones. This requires a balanced territorial development of the economy.

- Formation of agglomerations. The policy should be focused on the development of geographically linking transport and communication systems and infrastructures.

- Formation of the support framework of the settlements. Further increase of the economic density and the "contraction" of the territories, and a further development of cities.

Thus, urbanization and the formation of agglomerations around the megacities affect the issues of territorial distribution of industrial enterprises and transport infrastructure.

Therefore, there is a need for comprehensive strategic programs, which would secure the main directions of urban policy. They should include new forms and instruments of implementation (urban / municipal management system, urban autonomy, urban budgets, funding for urban infrastructure), with the inclusion of mechanisms for monitoring the implementation of government programs.

In general, the setting of an urbanized system, a territorial organization of economic potential and resettlement within the administrative-territorial reform carried out by the state, has an enormous role in the development of the economic potential of the whole country as a result, therefore it must necessarily be reflected in a steady eco-friendly economic development.

\section{REFERENCES}

1. Centre of Economic Research - CER (2010). Improving City Management System in Small and Medium Cities of Uzbekistan - Main Trends, Mechanisms and Instruments, Analytical Report 2010/04, United Nations Economic and Social Commission for Asia and the Pacific - UNESCAP, Tashkent. 
2. Centre of Economic Research - CER (2013). Urbanization in Central Asia: Challenges, Issues and Prospects. Analytical Report, United Nations Economic and Social Commission for Asia and the Pacific - UNESCAP, Tashkent, $70 \mathrm{p}$.

3. Dyldaev, M. M., Bokonbaev, K. J. (2008). Environmental problems of the city of Bishkek. Monograph, Bishkek, 124 p.

4. Gibbs, J. (1963). The evolution of the population concentration, Economic Geography, 39, 119-129.

5. http://central-asians.ru/

6. Lappo, G. M. (1997). Geografiya Gorodov, Edit. VLADOS, Moscow, 478 p.

7. Lucy, W.H. (1994). If planning includes too much, maybe it should include more, Journal of the American Planning Association, no. 60, 3, pp. 305 - 318.

8. MacRoberts, M. H., MacRoberts, Barbara (1989). Problems of citation analysis: A critical review. Journal of the American Society for Information Science, 1989, no. 40, 5, pp. $342-349$.

9. NISI (2015). Concept formation and development of the Bishkek agglomeration. Report, Bishkek, $35 \mathrm{p}$.

10. Office of Management and Budget (2013). Revised Delineations of Metropolitan Statistical Areas, Micropolitan Statistical Areas, and Combined Statistical Areas, and Guidance on Uses of the Delineations of These Areas, Bulletin No. 13-01 (February 28, 2013), c. 2, US Department of Labor, Washington DC.

11. Pertsik, E. N. (1991). Geografiya Gorodov (Geourbanistika), Vysshaya Shkola, 45 p.

12. Stiftel, B., Mogg Rebecca (2007). A planner's guide to the digital bibliographic revolution, Journal of the American Planning Association, no. 73, 1, pp. 68 - 85.

13. The Law of the Kyrgyz Republic (2008). On administrative-territorial structure of the Kyrgyz Republic, issued on April 25, 2008, No. 65, Bishkek.

14. The National Statistical Committee of the Kyrgyz Republic (2014). Annual Report, Bishkek, 129 p.

15. United Nations (2011). World Population Prospects: The 2010 Revision, UNDESA Population Division, New York.

16. USSR Statistics Committee (1987). National Economy of the USSR in 70 years: Anniversary Statistical Yearbook, Finance and Statistics, Moscow.

17. World Bank (2013). Planning, Connecting, and Financing Cities - Now: Priorities for City Leaders, World Bank, Washington DC. 